\title{
An aminoglycoside antibiotic gentamycin induces oxidative stress, reduces antioxidant reserve and impairs spermatogenesis in rats
}

\author{
Kilarkaje Narayana \\ Department of Anatomy, Faculty of Medicine, HSC, Kuwait University, Safat, Kuwait
}

(Received October 26, 2007; Accepted November 20, 2007)

\begin{abstract}
Gentamycin (GS) is an aminoglycoside antibiotic used to treat infections of various Gram-negative organisms. The present study was designed to investigate the effects of GS on oxidative stress, antioxidant levels, testicular structure and sperm parameters in the rat. Adult Wistar rats (12 week old; $\mathrm{N}=7 /$ group) were treated (i. p.) with $0 \mathrm{mg} / \mathrm{kg}, 3 \mathrm{mg} / \mathrm{kg}$ and $5 \mathrm{mg} / \mathrm{kg}$ for 10 days at an interval of 24 $\mathrm{hr}$ between subsequent treatments. Animals were sacrificed on days 1 and 35 after the last treatment, and the reproductive organs were removed and weights of testis and seminal vesicle were recorded. The right testis was processed for light microscopic analysis. The left testis was homogenized and step 19 spermatids were counted to determine the daily sperm production (DSP) and daily abnormal sperm production (DASP). The sperm count, sperm motility and incidence of abnormal sperms were estimated in the epididymis. In testicular sections, along with the evaluation of qualitative changes, the seminiferous tubule diameter (STD) and the epithelial height (SE) were measured. The incidence of stage XIV tubules in testicular sections, meiotic figures and step 14 spermatids/stage XIV tubule, and step 19 spermatids/stage VII tubule were estimated. Intra-testicular levels of superoxide anion, lipid peroxidation and antioxidantssuperoxide dismutase (SOD), catalase, glutathione peroxidase (GPx) and ascorbic acid were measured. GS did not affect the body weight, but the testis weight and DSP were decreased at $5 \mathrm{mg} / \mathrm{kg}$ dose-level on both days $(\mathrm{p}<0.05)$, and the weight of seminal vesicle decreased on day 35 at both dose-levels. The DASP was increased in a dose-dependent manner $(\mathrm{p}<0.05)$ on days 1 and 35 at both dose-levels. The sperm count was decreased at both dose-levels on day 35 , whereas the sperm motility was decreased and sperm abnormality was increased on day 1 at $5 \mathrm{mg} / \mathrm{kg}$ and on day 35 at both dose-levels. GS induced structural changes such as sloughing of seminiferous epithelium, vacuoles and gaps in the epithelium, nuclear pyknosis and atrophic changes in a few tubules. The tubular shrinkage was observed as indicated by decreased STD and SE on both days at $5 \mathrm{mg} / \mathrm{kg}$ dose-level. Incidence of stage XIV tubules and step 19 spermatids/stage VII tubule decreased on all time points at all dose-levels, whereas the step 14 spermatids and meiotic figures decreased on day 35 at both dose-levels $(\mathrm{p}<0.05)$. The free radical- superoxide anion concentration was significantly increased on day 1 in a dose-dependent pattern $(\mathrm{p}<0.05)$. However, activities of all 3 enzymatic antioxidants and ascorbic acid level decreased in a dose-dependent pattern on day 1 ( $\mathrm{p}<0.05$ ), except the GPx, which was also decreased on day 35 at $5 \mathrm{mg} / \mathrm{kg}$ dose-level. There was a significant rise in the thiobarbituric acid reactive substances on day 1 indicating increased lipid peroxidation in the testis. In conclusion, GS induces an oxidative stress-status in the testis by increasing free radical formation and lipid peroxidation, and by decreasing the antioxidant reserves. These biochemical changes manifest as structural and cytotoxic changes in the testis. Further, GS also affects the spermatozoa by affecting their number, motility and morphology.
\end{abstract}

Key words: Free radicals; Oxidative stress; Antibiotics; Spermatogenesis testis 


\section{INTRODUCTION}

Gentamycin (GS) is an aminoglycoside antibiotic produced by Micromonospora purpurea. It is used to treat septicaemia, including neonatal sepsis and other severe systemic infections of Gram-negative organisms (Reynolds, 1993; Klibi et al., 2007). It is administered to adults at the dose-levels of $3.0-5.0 \mathrm{mg} / \mathrm{kg}$ for a period ranging from 7-10 days, but in children doses range from 5.0-7.5 $\mathrm{mg} / \mathrm{kg}$ [1]. Although GS is a very effective antibiotic, its use is often limited owing to its toxicity to non-target tissues (Aust, 2001). It is now well known that GS is severely ototoxic, but its effects are severe on vestibular functions rather than that of the cochlea (Reynolds, 1993), and ototoxicity seems to be due to oxidative stress (Feldman et al., 2007), which could be counteracted by a number of antioxidants (Mostafa et al., 2007). Reversible nephrotoxicity is a dose-limiting adverse effect of GS, which generally leads to acute renal failure (Al-Majed et al., 2002). Nephrotoxicity is due to GS-induced generation of reactive oxygen species and reactive nitrogen species, which bind to anionic phospholipids that eventually destroy cellular membrane structure and functions (Ramsammy and Kaloyanides, 1987; Ali, 2003), and many antioxidants are known to have protective effects against these adverse effects (Sayed-Ahmed and Nagi, 2007).

There are a few studies addressing the effects of GS on reproductive system. Initially, it has been reported that GS would not accumulate in the testis owing to its poor transport across the blood testis barrier (Kataoka, 1983), although a later study, in contrast, reported an inhibition of cell division of germ cells and protein synthesis in the testis, and induction of cell death in the seminal vesicle (Timmermans, 1989). GS is also known to inhibit the activities of phosphatases in the reproductive organs and decrease in sperm count, ascorbic acid, steroidogenic enzymes and cholesterol levels in the testis (Ghosh and Dasgupta, 1999). Fifteen days after the therapy, the cholesterol and ascorbic acid levels recovered to the normal levels, whereas the dehydrogenase enzymes showed a considerable increase, and the authors concluded that GS affected the synthesis of testosterone (Ghosh and Dasgupta, 1999). GS also affected the sperm viability and function (Segovia et al., 2000), and inhibited the fertilizing ability and motility of spermatozoa (Ahmad et al., 1987). However, there are no studies reporting the effects of GS on oxidative stress, antioxidant levels, testicular structure and the evaluation of effects on sperm parameters are inadequate, in view of this, the present study was designed to investigate these effects of GS in the rat.

\section{MATERIALS AND METHODS}

\section{Animals}

Male Wistar rats (12-week-old; $180-190 \mathrm{~g}$ body weight) were housed in plastic cages under laboratory conditions of $12 \mathrm{~L}: 12 \mathrm{D}$ cycle; $22-25^{\circ} \mathrm{C}$ room temperature. The animals were procured from the Animal House of Kuwait University. All animals were treated in a humane manner, and maintained under standard ethical principles as per the Guidelines of Kuwait University and Federal Laws. All animals were acclimatized for a week before the onset of treatment. They were fed on laboratory chow and tap water ad libitum.

\section{GS treatment}

Animals were segregated into 6 groups of 7 rats in each. Two groups were treated (i. p.) only with water, which served as control. Two groups were treated with $3 \mathrm{mg} / \mathrm{kg}$, and the remaining two groups were treated (i. p.) with 5 $\mathrm{mg} / \mathrm{kg}$ (Ghosh and Dasgupta, 1999) of GS (Biochem Pharmaceutical industries, Mumbai), once daily at an interval of $24 \mathrm{hr}$ between successive treatments, for 10 days. The drug was dissolved in water for injection $(5 \mathrm{mg} / \mathrm{ml})$ just before the use. The dose-levels and duration of treatment were similar to human exposure regimen (Reynolds, 1993) except the route of exposure. The i. p. route was selected to treat the animals based on previous studies (Sayed-Ahmed and Nagi, 2007; Ghosh and Dasgupta, 1999), since it is an accurate and simple procedure. One control group and one group each from two dose-levels were sacrificed by lethal ether anesthesia on day 1, and another control group and one group each from two dose-levels were sacrificed on day 35, after the last treatment. Laparotomy was conducted to remove the reproductive tract, and the weights of testis and seminal vesicle were noted. The epididymis was processed for the evaluation of sperm parameters. The right testis was processed for light microscopic analysis, whereas the left testis was homogenized and used for evaluation of daily sperm production (DSP) and for biochemical analysis.

\section{Determination of DSP}

The testis was decapsulated and homogenized in phosphate-buffered saline (PBS, $5 \mathrm{ml} / \mathrm{g}$ testis; $\mathrm{pH}$ 7.35). The homogenate was kept in room temperature for $5 \mathrm{~min}$ and an aliquot was taken into leukocyte hemocytometer up to mark 0.5 and then diluted with phosphate-buffered saline up to mark 11 . The diluted homogenate was then discharged into a Neuabaur's counting chamber. The step 19 spermatid head count was done under a light microscope with $40 \mathrm{X}$ objective in 4 chambers and the DSP was calcu- 
Testicular effects of gentamycin.

lated by dividing the total count by 6.1 , which is the duration in days of spermatogenic cycle during which step 19 spermatids are present in the seminiferous epithelium (Fernades et al., 2007).

\section{Determination of daily abnormal sperm produc- tion (DASP)}

A part of the homogenate $(0.3 \mathrm{ml})$ was stained with eosin $\mathrm{Y}$ for $30 \mathrm{~min}$ in room temperature. An aliquot was taken into leukocyte hemocytometer as explained in the procedure to determine DSP, and charged into the Neuabaur's counting chamber. The step 19 spermatids with abnormal shapes of head or tail or of both were counted in 4 chambers under a light microscope with $40 \mathrm{X}$ objective. The total count was divided by 6.1 to determine the DASP.

\section{Sperm count, sperm motility and sperm morphol- ogy}

The epididymis was removed and cleaned off from the epididymal fat pad, and minced in $1 \mathrm{ml}$ of pre-warmed $\left(35^{\circ} \mathrm{C}\right) \mathrm{PBS}$, and filtered through $80 \mu \mathrm{m}$ pore-size nylon mesh. The filtrate was used for the evaluation of epididymal sperm parameters as follows. For sperm count, the filtrate was taken in a leukocyte hemocytometer up to mark 0.5 and then diluted with PBS up to mark 11. An aliquot of this suspension was charged into the Neuabaur's counting chamber and sperms were counted. The sperm count was expressed in millions/ml (Narayana et al., 2005a). To determine sperm motility, 100 sperms each were observed in 3 different fields, and classified into motile and nonmotile sperms, and the motility was expressed as percentage incidence. The sperm abnormality was assessed according to a standard procedure (Narayana et al., 2002, 2005a). Briefly, the smears of sperm suspension were made on clean glass slides and stained with periodic acidSchiff's reaction and hematoxylin. The stained smears were observed under a light microscope with $40 \mathrm{X}$ objective, and the sperms were classified into normal and abnormal. The total sperm abnormality was expressed as percentage incidence.

\section{Histopathology of testis}

The testis was fixed in Bouin's fluid, embedded in paraffin and $5 \mu \mathrm{m}$ thick sections were stained with periodic acid Schiff's reaction and hematoxylin and eosin. Sections were screened for any qualitative structural changes. The observation was made for possible structural changes such as epithelial sloughing, vacuoles and gaps in the epithelium, abnormal germ cells and tubular atrophy. The testis was also observed for cell death and missing cells in the epithelium. The structure of the Leydig cells was also observed. The seminiferous tubule diameter (STD) and epithelial height (SE; 10 tubules/testis) by an eyepiece micrometer calibrated with the stage micrometer (Narayana et al., 2006a).

In each testis, 50 randomly but transversely cut tubules were examined and the number of stage XIV tubules was recorded to express as percentage incidence. In 5 transversely cut stage XIV tubules, meiotic figures, step 14 spermatids and Sertoli cell nucleoli were counted, and expressed as incidence per Sertoli cell nucleolus (Narayana et al., 2006a). In each testis, 10 transversely cut stage VII tubules were identified and step 19 spermatids, which are androgen dependent, were counted and expressed as per tubule cross-section incidence (D'Souza and Narayana, 2002).

\section{Biochemical analysis of testis}

The testis homogenate was centrifuged at $800 \mathrm{rpm}$ for $20 \mathrm{~min}$ at $4^{\circ} \mathrm{C}$. The supernatant was used for biochemical analysis.

\section{Protein}

The protein level in the testis homogenate was assessed by Biuret method (Varley et al., 1980) to express other biochemical parameters as per mg protein.

\section{Superoxide anion}

Estimation of this free radical was based on a previously employed method (Podczasy and Wei, 1988; Latchoumycandane and Mathur, 2002). A reaction mixture was obtained by adding $4.9 \mathrm{mM}$ iodonitrotetrazolium violet, $0.3 \mathrm{mM}$ EDTA, and $0.92 \mathrm{mM}$ sodium carbonate ( $\mathrm{pH} 10.2$ ) to $25 \mu \mathrm{L}$ tissue homogenate. The tubes were then incubated for a period of $15 \mathrm{~min}$ and then kept in boiling water for a minute and then cooled to room temperature and the absorbance was read at $505 \mathrm{~nm}$ against blank (Latchoumycandane and Mathur, 2002).

\section{Estimation of enzymatic antioxidants}

The superoxide dismutase (SOD) in the testis was spectrophotometrically assayed by the method of Marklund and Marklund (Marklund and Marklund, 1974). A test mixture was obtained by mixing $300 \mu \mathrm{L}$ homogenate, 2.4 $\mathrm{ml} 50 \mathrm{mM}$ Tris- $\mathrm{HCl}$ containing $1 \mathrm{mM}$ EDTA ( $\mathrm{pH}$ 7.6) and $300 \mu \mathrm{L}$ of $0.2 \mathrm{mM}$ pyrogallol and the absorbance was read at $420 \mathrm{~nm}$ against the blank.

Catalase in the homogenate was assayed based on a spectrophotometric method (Claiborne, 1985). The test mixture was prepared by mixing $2.40 \mathrm{ml}$ of $50 \mathrm{mM}$ phosphate buffer ( $\mathrm{pH} 7)$, and $10 \mu \mathrm{L}$ of $19 \mathrm{mM}$ hydrogen perox- 
ide with $50 \mu \mathrm{L}$ homogenate. The absorbance was read at $240 \mathrm{~nm}$.

Glutathione peroxidase was estimated by a spectrophotometric method (Latchoumycandane and Mathur, 2002). The test mixture was prepared by mixing $10 \mu \mathrm{L}$ homogenate, $1.59 \mathrm{ml}$ of $100 \mathrm{mM}$ phosphate buffer ( $\mathrm{pH} 7.6), 100$ $\mu \mathrm{L}$ of $10 \mathrm{mM}$ EDTA, $50 \mu \mathrm{L}$ of glutathione reductase, 100 $\mu \mathrm{L}$ sodium azide, $100 \mu \mathrm{L}$ of reduced glutathione, $100 \mu \mathrm{L}$ of $200 \mathrm{mM}$ NADPH and $10 \mu \mathrm{L}$ hydrogen peroxide. The absorbance was read at $340 \mathrm{~nm}$ against blank.

\section{Ascorbic acid}

Ascorbic acid level was calorimetricaly measured by 2, 4-dinitrophenyl hydrazine method (Kaplan and Pesce, 1987; Narayana et al., 2005a). Briefly, ascorbic acid in the homogenate is oxidized by $\mathrm{Cu}^{+2}$ to form dihydro-ascorbic acid that reacts with acidic 4-dinitrophenyl hydrazine to form a hydrazone, which is red in color. The absorbance of this product was read at $520 \mathrm{~nm}$.

\section{Lipid peroxidation}

The lipid peroxidation was estimated by a spectrophotometric method in terms of thiobarbituric acid reactive substances (Latchoumycandane and Mathur, 2002). One volume of homogenate was mixed with 2 volume of stock reagent $(15 \% \mathrm{w} / \mathrm{v}$ trichloroacetic acid in $0.25 \mathrm{~N} \mathrm{HCl}$, and $0.375 \% \mathrm{w} / \mathrm{v}$ thiobarbituric acid in $0.25 \mathrm{~N} \mathrm{HCl}$ ) in a centrifuge tube, vortexed, and heated for $15 \mathrm{~min}$ in a water bath. The mixture was cooled, centrifuged at $2500 \mathrm{rpm}$ for 10 min and the absorbance of the supernatant was read at 532 nm against blank.

\section{Statistical analysis}

Data for each group ( $\mathrm{N}=7)$ were expressed as mean \pm S.D. and compared for statistical significance by one way
ANOVA followed by Bonferroni's post hoc test and $\mathrm{p}$ value $<0.05$ was considered as a significant difference.

\section{RESULTS}

Treatment of GS for 10 days did not significantly affect the body weight of rats although a minor variation was observed in $5 \mathrm{mg} / \mathrm{kg}$ treated groups (Table 1). There were no changes in body weight during treatment, either (data not shown). Nevertheless, GS decreased the testis weight on days 1 and 35 , but only at the dose-level of $5 \mathrm{mg} / \mathrm{kg}$ $(\mathrm{p}<0.05)$. There was no effect of $3 \mathrm{mg} / \mathrm{kg}$ dose-level on the testis weight, although a decrease was observed without any statistical significance (Table 1). The treatment of GS did not induce any significant changes in the weight of seminal vesicle on day 1 , although there was a marginal decrease. On the other hand, there was a significant decrease in the weight of this organ on day 35 in a dosedependent manner $(p<0.05$; Table 1$)$. Similar to reduced testis weight, the DSP was also reduced only at $5 \mathrm{mg} / \mathrm{kg}$ on both sample days $(p<0.05)$, although the same was observed at $3 \mathrm{mg} / \mathrm{kg}$ dose-level, but without any statistical significance. The DASP, on the other hand, increased at both dose-levels on days 1 and $35(\mathrm{p}<0.05)$ in a dosedependent manner (Table 1). Nevertheless, the maximum effect was seen on day 1 at $5 \mathrm{mg} / \mathrm{kg}$ dose-level. Increase in DASP was around 3-4 times more than control on day 1, and around 2-2.5 times on day 35 indicating that the effect was more on day 1 . The sperm count did not significantly differ in the treated groups from that of the control on day 1 , whereas on day 35, a significant decrease was observed, and the effect was in a dose-dependent manner (Table 1). On day 35 , the reduction in sperm concentration was up to one half and one fourth of the control level at $3 \mathrm{mg} / \mathrm{kg}$ and $5 \mathrm{mg} / \mathrm{kg}$ dose-levels, respectively. The sperm motility was

Table 1. Effect of GS on different toxicity parameters in the rat.

\begin{tabular}{|c|c|c|c|c|c|c|}
\hline \multirow{3}{*}{$\begin{array}{l}\text { Parameter } \\
\text { Final body weight }(\mathrm{g})\end{array}$} & \multicolumn{3}{|c|}{$1 \mathrm{~d}$} & \multicolumn{3}{|c|}{$35 \mathrm{~d}$} \\
\hline & Control & $3 \mathrm{mg} / \mathrm{kg}$ & $5 \mathrm{mg} / \mathrm{kg}$ & Control & $3 \mathrm{mg} / \mathrm{kg}$ & $5 \mathrm{mg} / \mathrm{kg}$ \\
\hline & $200.50 \pm 3.21$ & $201.90 \pm 4.27$ & $198.63 \pm 5.45$ & $215.84 \pm 4.12$ & $217.45 \pm 4.61$ & $214.32 \pm 3.89$ \\
\hline Testis $(\mathrm{g})$ & $1.65 \pm 0.11$ & $1.62 \pm 0.43$ & $1.45 \pm 0.22 *$ & $1.70 \pm 0.89$ & $1.69 \pm 0.19$ & $1.57 \pm 0.14^{*}$ \\
\hline Seminal vesicle $(\mathrm{g})$ & $0.881 \pm 0.05$ & $0.873 \pm 0.12$ & $0.874 \pm 1.12$ & $0.921 \pm 1.25$ & $0.861 \pm 0.06^{*}$ & $0.858 \pm 0.04 *$ \\
\hline $\operatorname{DSP}\left(\times 10^{6}\right)$ & $32.80 \pm 1.00$ & $31.10 \pm 0.90$ & $28.20 \pm 0.30 *$ & $34.16 \pm 0.76$ & $31.88 \pm 0.89$ & $30.12 \pm 0.42 *$ \\
\hline DASP $\left(\times 10^{6}\right)$ & $2.11 \pm 0.12$ & $7.31 \pm 0.43^{*}$ & $9.77 \pm 0.23 *$ & $3.12 \pm 0.13$ & $6.13 \pm 0.21 *$ & $8.68 \pm 0.11 *$ \\
\hline Sperm count $\left(\times 10^{6}\right)$ & $12.00 \pm 1.20$ & $11.20 \pm 0.50$ & $11.70 \pm 1.32$ & $14.12 \pm 1.23$ & $7.34 \pm 0.34 *$ & $4.15 \pm 0.23^{*}$ \\
\hline$\%$ Sperm motility & $75.32 \pm 3.15$ & $70.14 \pm 4.12$ & $64.10 \pm 1.30^{*}$ & $72.19 \pm 2.30$ & $60.14 \pm 0.23 *$ & $49.34 \pm 0.33 *$ \\
\hline$\%$ Sperm abnormality & $2.34 \pm 0.05$ & $3.41 \pm 0.72$ & $7.17 \pm 0.22 *$ & $3.45 \pm 0.11$ & $18.23 \pm 0.12 *$ & $24.14 \pm 0.24 *$ \\
\hline
\end{tabular}

Data are represented as mean \pm S.D. $(\mathrm{N}=7) .{ }^{*} \mathrm{p}<0.05$, control versus treated. $\mathrm{DSP}=$ Daily sperm production; DASP= Daily abnormal sperm production. 
Testicular effects of gentamycin.

decreased on day 1 at $5 \mathrm{mg} / \mathrm{kg}$ dose-level, whereas on day 35 , the decrease was seen in both treated groups. The maximum effect was seen on day 35 at $5 \mathrm{mg} / \mathrm{kg}$ dose-level. On the other hand, the incidence of abnormal sperms increased on day 1 at $5 \mathrm{mg} / \mathrm{kg}$ dose-level, and on day 35 at both dose-levels, in a dose-dependent manner (Table 1). Increase in the incidence of abnormal sperms was more than double on day 1 at $5 \mathrm{mg} / \mathrm{kg}$ dose-level, and around 5 to 7 times on day 35 at $3 \mathrm{mg} / \mathrm{kg}$ and $5 \mathrm{mg} / \mathrm{kg}$ dose-levels, respectively (Table 1 ).

GS did induce structural changes in the testis such as epithelial sloughing, epithelial gaps and germ cell degeneration. These changes were obvious on day 35 rather than on day 1 (Fig. 1). A very few tubules showed atrophic changes on day 35. In GS treated rats, some seminiferous tubules showed disrupted cell associations (Fig. 1B). Some tubules showed cellular degeneration and atrophic changes, and a few other tubules showed atrophy, although the majority of tubules were normal. In some stage VII or VIII tubules, empty spaces in the epithelium were observed due to missing germ cells (Fig. 1C). These degenerative changes led to tubular atrophy (Fig. 1D), but
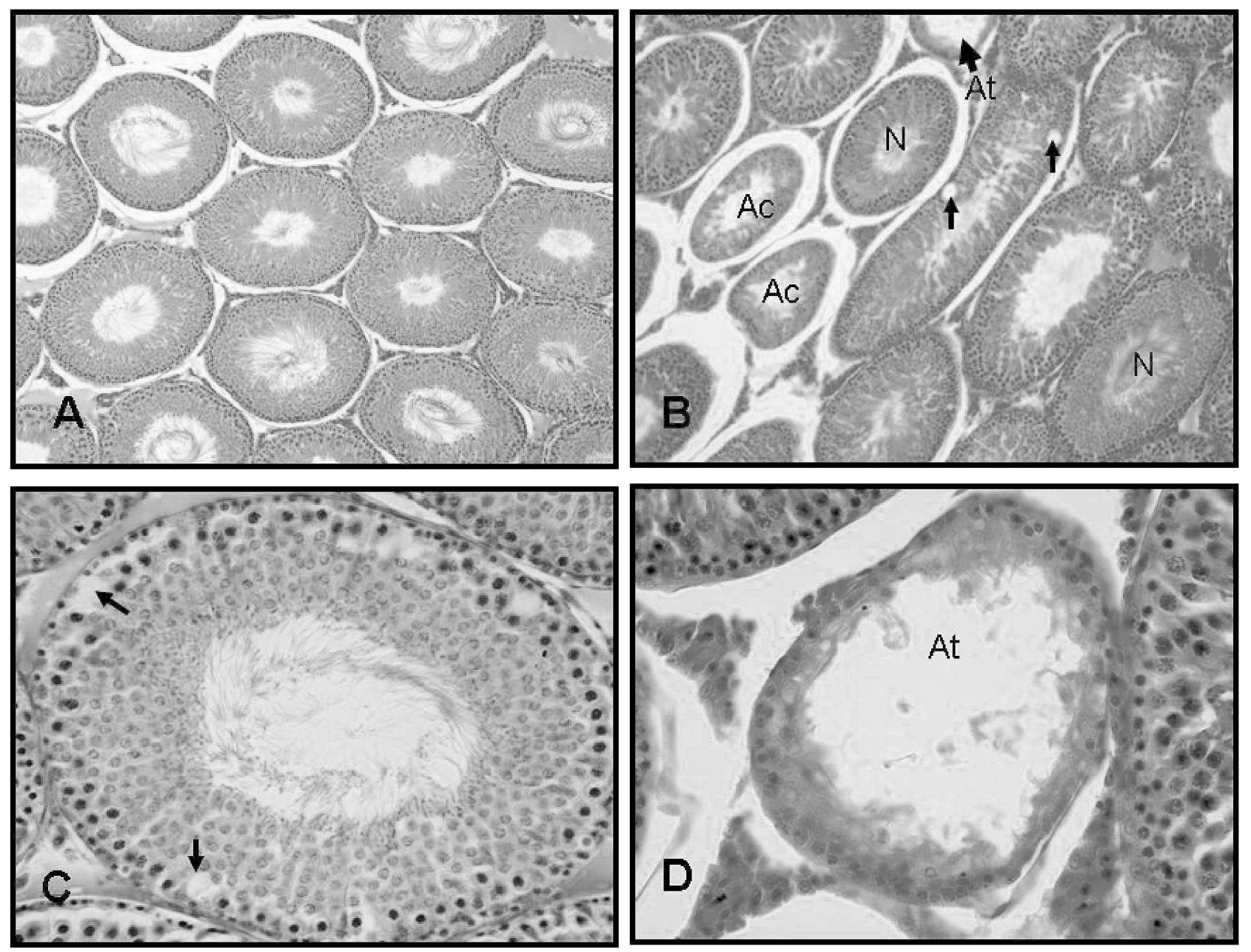

Fig. 1. GS-induced structural changes in the testis. A) A testicular section from the control rat showing normal seminiferous tubules, B) A testicular section from the rat treated with $5 \mathrm{mg} / \mathrm{kg}$ on day 35 . Note that a few tubules are showing atrophic changes (Ac) while other tubules are normal $(\mathrm{N})$. At the upper border of the photograph, a tubule is showing atrophy (At) and vacuoles in the epithelium are indicated by small arrows, C) A stage VII seminiferous tubule from the rat treated with $5 \mathrm{mg} / \mathrm{kg}$ on day 35 showing spaces (arrows) appeared due to cell death and, D) A tubular section from the testis of a rat treated with $5 \mathrm{mg} / \mathrm{kg}$ on day 35 indicating atrophy (At).PAS \& H\&E, A and $B=100 X ; C$ and $D=450 X$ (original magnification). 
not many such tubules were seen. In atrophic tubules, Sertoli cells and spermatogonia were seen, but not the spermatocytes and spermatids. The GS treatment induced a significant tubular shrinkage as indicated by decreased STD on both sample days, but the maximum effect was seen on day 35 , at $5 \mathrm{mg} / \mathrm{kg}$ dose-level (Table 2). Concomitantly, the thickness of the seminiferous epithelium was decreased at $5 \mathrm{mg} / \mathrm{kg}$ dose-level. Cytotoxicity was indicated in terms of decreased incidences of stage XIV tubules on both sample days, whereas a reduction in meiotic figures and step 14 spermatids in stage XIV tubules was seen only on day 35 (Table 2). The incidence of step 19 spermatids decreased on both sampling days $(\mathrm{p}<0.05)$. The effect on step 19 spermatids was in a dose-dependent pattern and the effect was more on day 35 than on day 1 (Table 2).

GS induced oxidative stress as indicated by increased concentration of superoxide anion in a dose-dependent pattern, but only on day 1 , not on day 35 , at which time point a recovery was observed (Fig. 2). On the other hand, the concentration of SOD was decreased in a dose-dependent pattern, but only on day 1 . On day 35 , a complete recovery was observed (Fig. 3). The concentration of catalase was also found decreased on day 1 . Even though a mild reduction was observed on day 35 in treated groups, the change was not statistically significant (Fig. 4). The GPx level was also found decreased on day 1, but without any dose-dependent pattern. However, on day 35 , the

Table 2. Effect of GS on seminiferous tubules in the rat.

\begin{tabular}{lccrrrr}
\hline Parameter & \multicolumn{3}{c}{$1 \mathrm{~d}$} & \multicolumn{2}{c}{$35 \mathrm{~d}$} \\
\hline STD $(\mu \mathrm{m})$ & Control & $3 \mathrm{mg} / \mathrm{kg}$ & $5 \mathrm{mg} / \mathrm{kg}$ & \multicolumn{1}{c}{ Control } & \multicolumn{1}{c}{$3 \mathrm{mg} / \mathrm{kg}$} & $5 \mathrm{mg} / \mathrm{kg}$ \\
SE $(\mu \mathrm{m})$ & $325.02 \pm 2.03$ & $323.13 \pm 4.33$ & $311.45 \pm 2.11^{*}$ & $328.36 \pm 2.99$ & $326.88 \pm 1.22$ & $308.01 \pm 1.02^{*}$ \\
\% Stage XIV tubules & $74.82 \pm 1.91$ & $72.43 \pm 2.13$ & $68.02 \pm 0.87^{*}$ & $75.68 \pm 2.22$ & $73.56 \pm 2.19$ & $69.22 \pm 1.01^{*}$ \\
ES/SN & $7.28 \pm 0.89$ & $4.12 \pm 1.08^{*}$ & $4.01 \pm 0.85^{*}$ & $8.11 \pm 0.44$ & $5.12 \pm 0.23^{*}$ & $4.21 \pm 0.11^{*}$ \\
MF/SN & $3.33 \pm 0.52$ & $3.67 \pm 0.87$ & $4.42 \pm 1.22$ & $4.56 \pm 0.54$ & $2.11 \pm 0.22^{*}$ & $1.51 \pm 0.43^{*}$ \\
Step 19 spermatids & $8.34 \pm 0.56$ & $9.23 \pm 1.23$ & $7.67 \pm 1.56$ & $9.35 \pm 0.25$ & $4.37 \pm 0.56^{*}$ & $3.11 \pm 0.67^{*}$ \\
/Stage VII tubule & $138.60 \pm 2.14$ & $128.21 \pm 1.12^{*}$ & $121.33 \pm 1.43^{*}$ & $130.37 \pm 3.21$ & $121.13 \pm 1.13^{*}$ & $111.22 \pm 1.98^{*}$ \\
section & & & & & \\
\hline
\end{tabular}

Data are represented as mean \pm S.D. $(\mathrm{N}=7)$. $* \mathrm{p}<0.05$, control versus treated. $\mathrm{STD}=$ Seminiferous tubule diameter; $\mathrm{SE}=\mathrm{Seminiferous}$ epithelial height; ES/SN=Elongated spermatids (step14)/Sertoli cell nucleolus; and MF/SN=Meiotic figures/ Sertoli cell nucleolus.

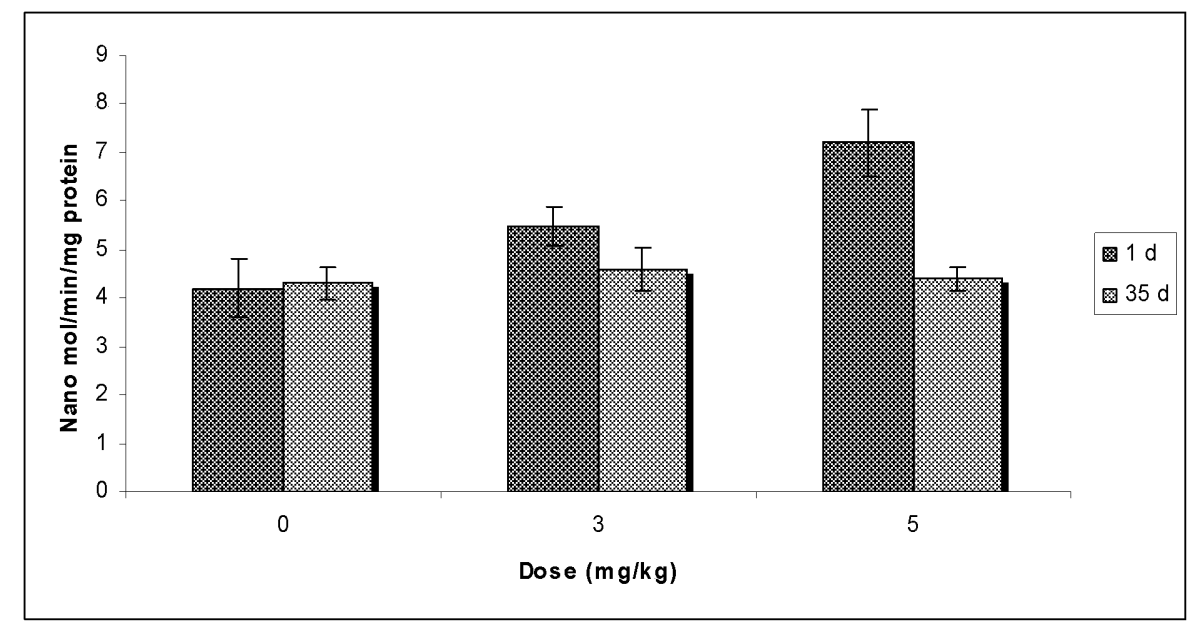

Fig. 2. Superoxide anion concentration in the testis homogenate of GS treated rats. Data are represented as mean \pm S.D. $(N=7)$. $p<0.05$, control versus treated on day 1 . On day 35 , there was no significant effect on superoxide anion level. 
Testicular effects of gentamycin.

decrease was significant only at $5 \mathrm{mg} / \mathrm{kg}$ dose-level (Fig. $5)$. The intra-testicular level of a non-enzymatic antioxidant-ascorbic acid was decreased on day 1 in a dosedependent pattern, but without any significant effect on day 35 (Fig. 6). The GS treatment resulted in increase in the concentration of thiobarbituric acid reactive substances in a dose-dependent pattern on day 1 , but not on day 35 (Fig. 7).

\section{DISCUSSION}

GS is a widely and most commonly used drug against

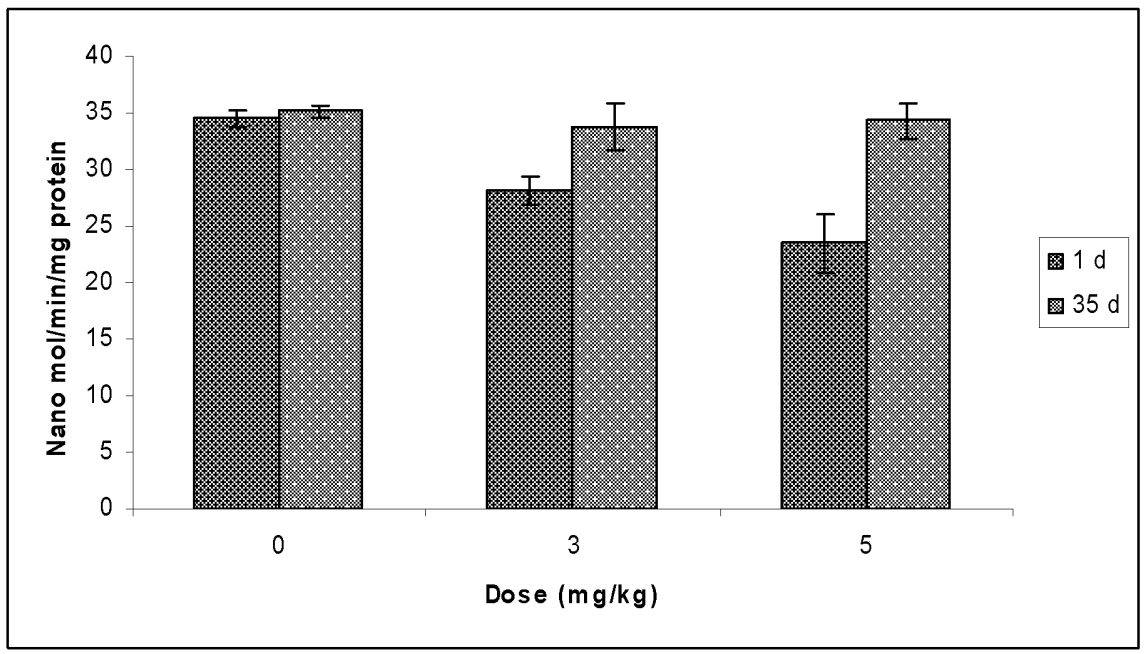

Fig. 3. Superoxide dismutase (SOD) concentration in the testis homogenate of GS treated rats. Data are represented as mean \pm S.D. $(\mathrm{N}=7)$. $\mathrm{p}<0.05$, control versus treated on day 1 . On day 35 , there was no significant effect on SOD level.

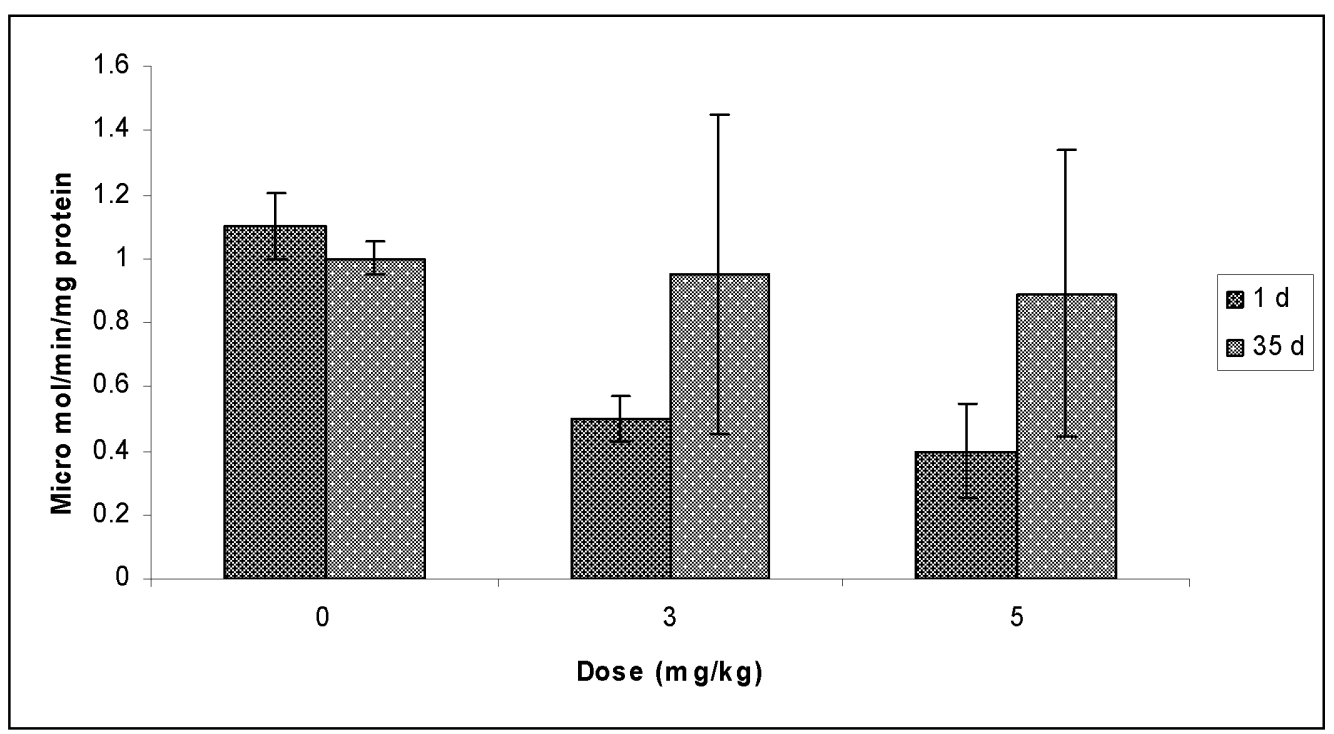

Fig. 4. Catalase concentration in the testis homogenate of GS treated rats. Data are represented as mean \pm S.D. $(\mathrm{N}=7)$. $\mathrm{p}<0.05$, control versus treated on day 1 . On day 35 , there was no significant effect on catalase level. 
many Gram-negative infections. Nevertheless, GS induces acute renal failure, which is, in fact a dose-limiting effect of this drug, leading to increased morbidity and health care costs (Al-Majed et al., 2002; Sayed-Ahmed and Nagi,
2007). The acute renal failure is due to the induction of an oxidative stress- status in the kidney, in which case, reactive oxygen species and reactive nitrogen species increase and antioxidants decrease with concomitant increase in

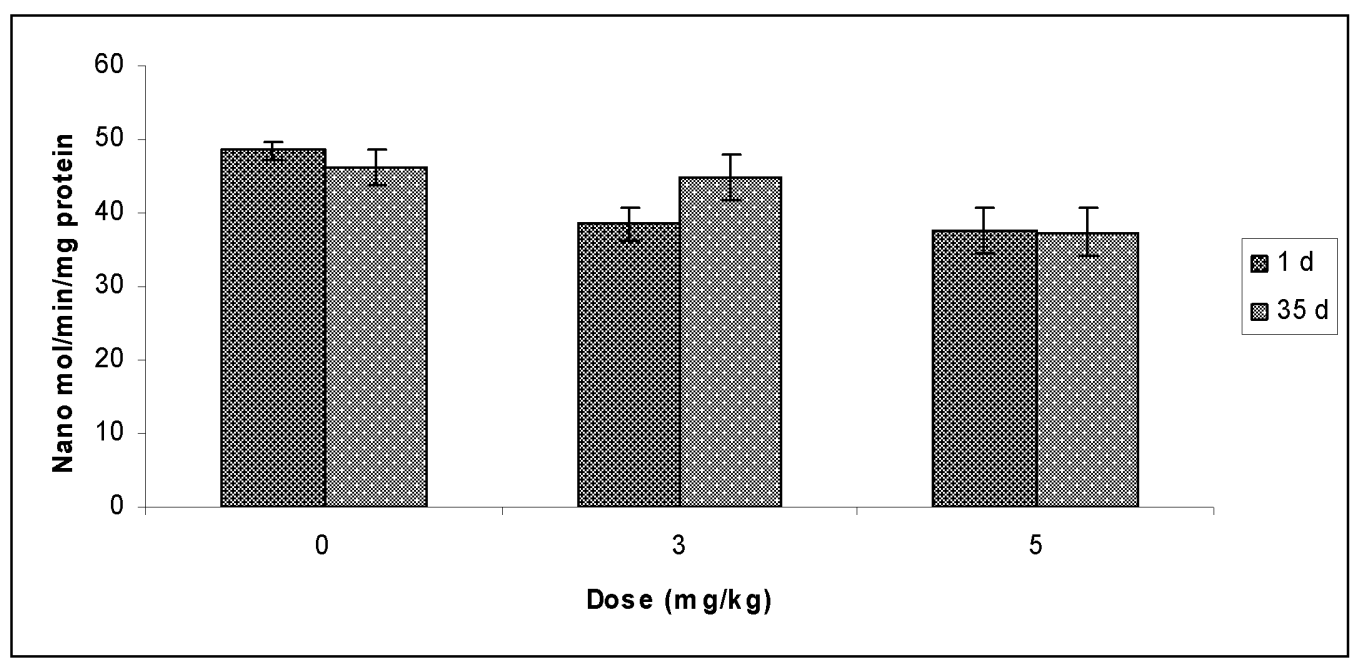

Fig. 5. Glutathione peroxidase (GPx) concentration in the testis homogenate of GS treated rats. Data are represented as mean \pm S.D. $(\mathrm{N}=7)$. $\mathrm{p}<0.05$, control versus treated on day 1 at both dose-levels, and on day 35 , the significant effect was observed only at $5 \mathrm{mg} / \mathrm{kg}$ dose-level.

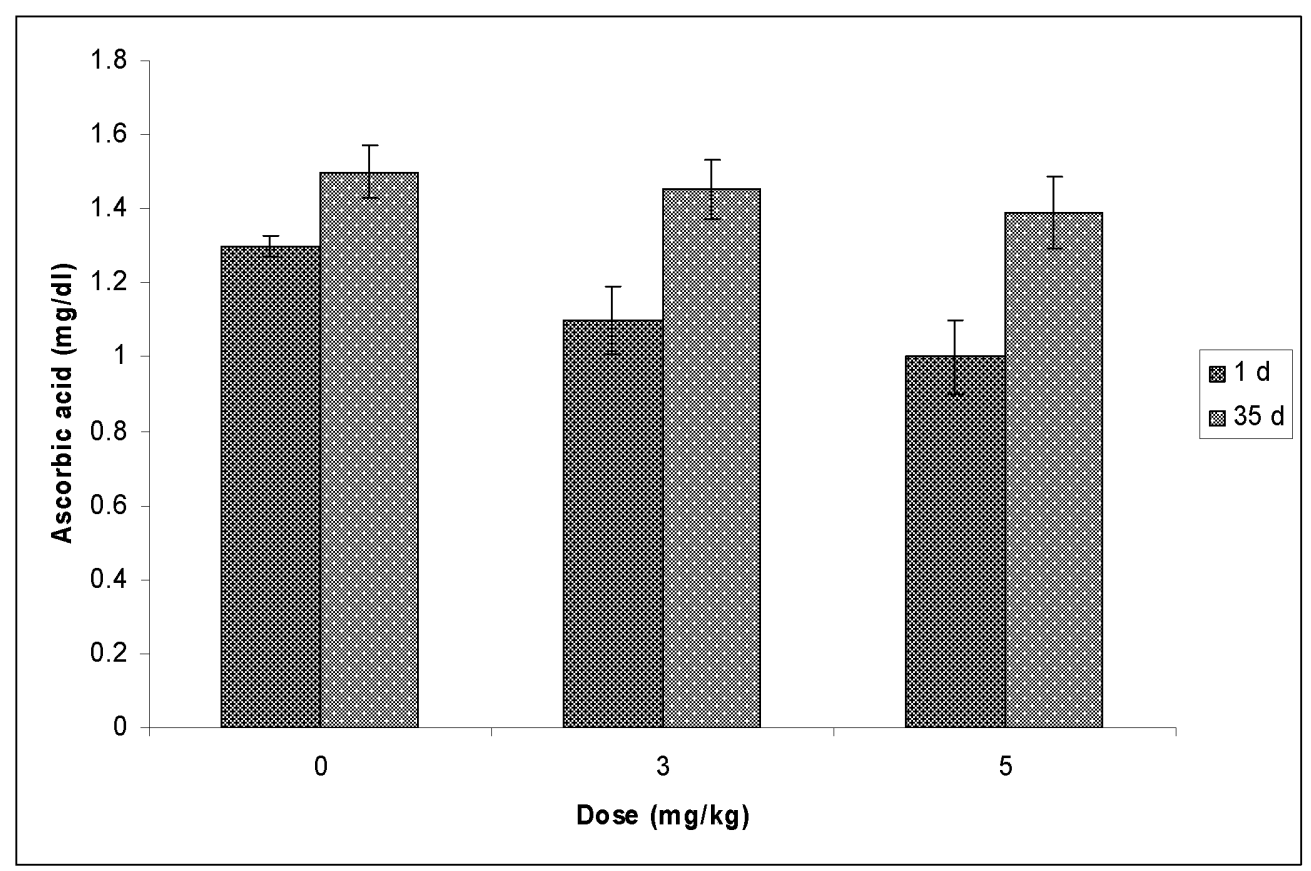

Fig. 6. Ascorbic acid concentration in the testis homogenate of GS treated rats. Data are represented as mean \pm S.D. $(\mathrm{N}=7)$. $\mathrm{p}<0.05$, control versus treated on day 1 and on day 35 , there was no significant effect. 
Testicular effects of gentamycin.

lipid peroxidation and membrane damage, which would eventually end up in structural changes (Ramasammy and Kaloyanides, 1987; Walker et al., 1999). Several studies have revealed that treatment of antioxidants such as vitamins C and E (Kadkhodaee et al., 2007), curcumin (Ali, 2003) and thymoquinone and several other agents, prevents the GS-induced oxidative stress related nephrotoxicity in animal models (Sayed-Ahmed and Nagi, 2007).

For our knowledge, this is the first study to reveal the GS-induced oxidative stress, decreased antioxidant levels, lipid peroxidation and histopathological changes in the testis. There were no significant changes in the body weight during treatment (data not shown) or in the final body weight (Table 1) indicating that GS was unable to induce a significant effect on general health conditions of rats. Decreased testis weight at a higher dose-level was due to structural changes (Narayana et al., 2006b). Histopathological changes such as epithelial cell sloughing, atrophic changes and decrease in germ cell numbers due to cytotoxicity (vide infra) were the factors responsible for decrease in the testis weight and this relation has been very well established in various other experimental conditions (Hess et al., 1988; Hess and Nakai, 2000; Narayana et al., 2006b). Further, decrease in DSP correlated with decrease in the testis weight indicating that the germ cell death, as previously reported (Timmermans, 1989), or cell loss from the epithelium by other means such as epithelial sloughing or tubular atrophy was the main reason for decreased testis weight. Decrease in germ cell number might be due to an effect on testosterone level as indicated by reduced weight of an androgen-dependent organ-seminal vesicle (Table 1). Since GS has the ability to induce cell death in the seminal vesicle (Timmermans, 1989), which would contribute to weight reduction, it is highly likely that testosterone level should be responsible for decreased seminal vesicle weight (Latchoumycandane and Mathur, 2002). Although the testosterone level has not been estimated in the present study, it has been previously reported that GS was able to reduce the rate limiting enzymes of testosterone synthesis, indicating a hindered production of the latter (Ghosh and Dasgupta, 1999). Decrease in sperm count, on the other hand, was observed only on day 35 indicating the cytotoxicity of the drug. However, there was no significant effect on sperm count on day 1 in the present study, because the sampling time was too early to detect the effects. The sperms sampled on day 1 after the last treatments were the ones in the testis as elongated spermatids, during exposure. The germ cells, which were exposed to the drug, did not reach the epididymis when the latter was sampled or decrease in sperm number did not reach a statistically significant level (Table 1). The germ cells undergoing the process of spermatogenesis were affected by the drug, and the left-over germ cells appeared as spermatozoa on day 35 , but less in number $(\mathrm{p}<0.05)$. This effect of the drug was directly dependent on the strength of the dose (Table 1). The fact that the cytotoxicity of the drug during the treat-

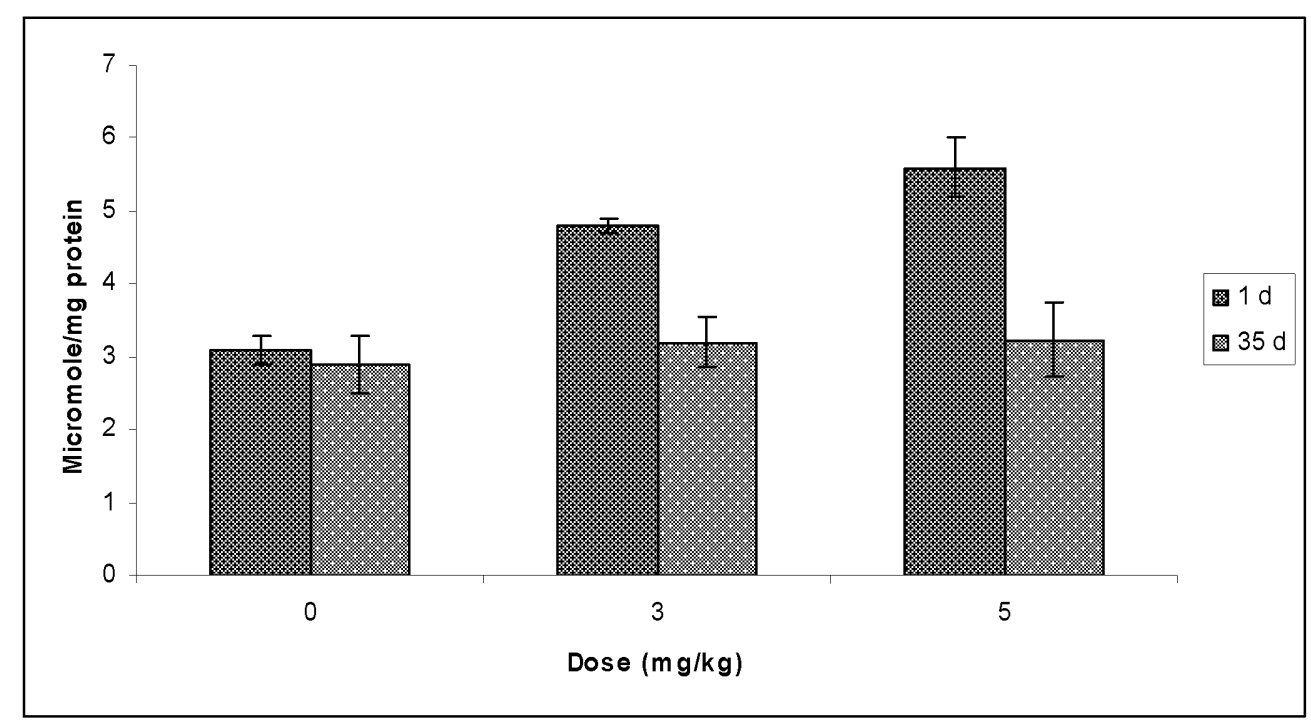

Fig. 7. Lipid peroxidation in terms of thiobarbituric acid reactive substances in the testis homogenate of GS treated rats. Data are represented as mean \pm S.D. $(N=7)$. $p<0.05$, control versus treated on day 1 and on day 35 , showed no significant effect. 
ment manifested as decrease in sperm count on day 35 was further justified by a decrease in the DSP on day 1 at a higher dose level, which persisted over an extended period of time on day 35. This fact has also been further supported by a decrease in step 19 spermatids/stage VII tubule, which is an indicator of cytotoxicity (D'Souza and Narayana, 2002).

On the other hand, GS has had an effect on morphogenesis of spermatozoa as indicated by abnormal step 19 spermatid shapes, which increased in terms of DASP, in a dose-dependent manner. Observation of an elevated level of DASP even on day 35 indicates that GS has a prolonged effect on morphogenesis of germ cells. As yet another toxic effect, the sperm motility was decreased, especially on day 35 (Table 1), which indicates that GS affects the flagellar functions of the spermatozoa probably by affecting the structure. Decrease in sperm motility was taken place in a direct relation with an increase in the incidences of abnormal sperms. The sperm motility and abnormalities were affected on day 1 at a higher dose-level indicating that the oxidative stress was induced in the epididymis, although that has not been investigated in this study. This biochemical change would have been toxic to the sperms, resulting in DNA damage (Aitken and Krausz, 2001), independent of those in the testis. Although the damage of germ cells in the testis appears to be a reason for impaired sperm quality, a possibility of oxidative stress in the epididymis might be yet another reason for this. The reactive oxygen species may cause lipid peroxidation of sperm cell membranes hence damaging the midpiece, axonemal structure, or disrupting the capacitation and acrosomal reaction, finally leading to infertility (Tramer et al., 1998). This indicates that the sperm abnormalities-a sensitive marker of germ cell damage-seen on day 1 might be due to free radicals- induced damage in the epididymis, in addition to that in the testis, or independent of the latter. Abnormal sperm morphology occurs due to many drug-induced effects including germ cell DNA damage, Y chromosomal abnormalities, defective acrosome formation, defective protein synthesis and somatic cell damage in the testis (Wyrobek et al., 1983; Narayana et al., 2002; Narayana et al., 2005a). Increase in sperm abnormality, and decrease in sperm count and sperm motility are associated with decreased fertility (Wyrobek et al., 1983; Narayana et al., 2002) and all these three spermatotoxic parameters are related to DNA fragmentation (Tramer et al., 1998).

Decrease in STD and SE indicates the tubular shrinkage (Hess and Nakai, 2000), and interestingly, this took place concomitantly with decreased testis weight and DSP. The STD and SE are good indicators of tubular integrity, which are decreased when the tubules suffer from cell loss either due to sloughing or cytotoxicity (Narayana et al., 2006b). The latter two types of structural changes were seen in the present study. The tubular atrophy seen in a few tubules on day 35 indicate that GS induced significant structural changes leading to germ cell loss and finally reduced sperm production. It is unknown whether or not GS disrupts intercellular bridges in the seminiferous epithelium, which would finally end up in total testicular atrophy (Hess and Nakai, 2000). The processes preceding tubular atrophy were very clear in the testis. Firstly, the seminiferous epithelium showed signs of disruption in terms of vacuoles, sloughing and cell degeneration. Secondly, the process of cell loss was contributed by cell death, as indicated by empty spaces in the epithelium and cellular degeneration evidenced by nuclear pyknosis. Thirdly, the cell loss from the epithelium, led to tubular shrinkage and finally to tubular atrophy. Decrease in frequency of stage XIV tubules indicates that the GS has an inhibitory effect on progression of epithelial cycle in the testis, which would obviously reduce the sperm number. In addition, the meiotic figures in the stage XIV tubules and consequently the elongating spermatids (step 14) in them decreased as an indicator of cytotoxicity (Narayana et al., 2006b). This adverse effect was also reflected in terms of reduced DSP, step 19 spermatids/stage VII-tubule- a testosterone dependent mechanism (De Franca et al., 1994) -and sperm count.

In the present study, GS induced the oxidative stress by increasing the free radical formation, lipid peroxidation and decreasing the antioxidant levels. SOD dismutates the superoxide anion to hydrogen peroxide and molecular oxygen. On the other hand, decrease in catalase levels would result in accumulation of hydrogen peroxide. Also, catalase and GPx protect SOD against the effects of hydrogen peroxide (Marklund and Marklund, 1974). Since ascorbic acid, the level of which has been decreased in the present study, also protects the tissues from oxidative stress- induced damage (Narayana et al., 2005a), a clear oxidative stress has been achieved in the testis. Lipid peroxidation is a process of oxidative degradation of polyunsaturated fatty acids that result in impaired membrane structure and function (Goel et al., 2005). Free radicals, otherwise damage cellular lipids by binding to membrane anionic phospholipids (Walker et al., 1999; Sayed-Ahmed and Nagi, 2007), proteins and DNA, finally the entire cell (Mates et al., 1999). Antioxidants, being free radical scavengers hamper the destructive effects of the latter on cells and tissues. GS-induced oxidative stress in the kidney resulted in glomerular and tubular necrosis, and dilatation of tubular lumen and acute renal failure (Sayed-Ahmed and Nagi, 2007). GS is known to increase nitrite/nitrate 
Testicular effects of gentamycin.

ratio as a measure of nitric oxide production, and thiobarbuteric acid reactive substances in the kidney, which had a positive correlation with structural changes in the kidney (Sayed-Ahmed and Nagi, 2007). This phenomenon would have been responsible for structural changes such as vacuoles, gaps, cytotoxicity and atrophic changes in the testis and spermatozoa. The vacuoles and gaps in the seminiferous epithelium appear due to dilatation of endoplasmic reticulum in Sertoli cells (De Krester and Kerr, 1994), and missing of germ cells from the epithelium (Narayana et al., 2005 b), respectively. The oxidative stress in the testis should have affected the structure and functions of cell organelles that manifested as histopathological changes. Since the oxidative stress-status induces cellular and DNA damage (Tramer et al., 1998), it is possible that the cell death and consequent tubular atrophy, at least in a few tubules, would have been the response of seminiferous epithelium to altered biochemical milieu in the testis. These results therefore indicate that the oxidative stress induced owing to an imbalance between the free radicals and oxidants, has a key role in initiating tubular damage in the testis, just as it does in the kidneys (Sayed-Ahmed and Nagi, 2007).

In conclusion, GS induces an oxidative stress- status by increasing free radical formation and lipid peroxidation, and by decreasing the antioxidant reserves resulting in structural and cytotoxic changes in the testis. Further, GS also induces changes in sperms by affecting their number, motility and morphology.

\section{ACKNOWLEDGMENT}

I thank Ms. Susan Verghese, Department of Anatomy at Kuwait University, for her technical assistance.

\section{REFERENCES}

Ahmad, K., Foote, R.H. and Kaproth, M. (1987): Antibiotics for bull semen frozen in milk and egg yolk extenders. J. Dairy. Sci., 70, 24392443.

Aitken, R.J. and Krausz, C. (2001): Oxidative stress, DNA damage and the Y chromosome. Reproduction., 122, 497-506.

Ali, B. H. (2003): Agents ameliorating or augmenting experimental gentamicin nephrotoxicity. Some recent research. Food. Chem. Toxicol., 41, 1447-1452.

Al-Majed, A.A., Mostafa, A.M., Al-Rikabi, A.C. and Al-Shabana, O.A. (2002): Protective effects of oral Arabic gum administration on gentamicin induced nephrotoxicity in rats. Pharmacol. Res., 46, 445-451.

Aust, G. (2001): Vestibulotoxicity and ototoxicity of gentamicin in newborns at risk. Int. Tinnitus. J., 7, 27-29.

Claiborne, A. (1985): Handbook of methods for oxygen radical research. (Greenwald, R., ed.), pp.283-284. CRC Press, Florida.

D’Souza, U.J.A. and Narayana, K. (2002): Mechanism of cytotoxicity of ribavirin in the rat bone marrow and testis. Indian. J. Physiol. Pharma- col., 46, 468-474.

De Franca, L.R., Jackson, A. and Russell, L.D. (1994): Hormone sensitivity of germ cells in stage XIV and in stage I of the rat spermatogenic cycle. Tissue. Cell., 26, 375-383.

De Krester, D.M. and Kerr, J.B. (1994): The cytology of the testis. In (Knobil, N.E. and Neil, J.D., eds.), pp.1177-1280. The physiology of reproduction. $2^{\text {nd }}$ Ed. Raven Press Ltd. New York.

Feldman, L., Efrati, S., Eviatar, E., Abramsohn, R., Yarovoy, I., Gersch, E., Averbukh, Z. and Weissgarten, J. (2007): Gentamicin-induced ototoxicity in hemodialysis patients is ameliorated by $\mathrm{N}$-acetylcysteine. Kidney. Int., 72, 359-363.

Fernades, G.S.A., Arena, A.C., Fernandez, C.D.B., Mercadante, A., Barbisan, L.F. and Kempinas, W.G. (2007): Reproductive effects in male rats exposed to diuron. Reprod.Toxicol., 23, 106-112.

Ghosh, S. and Dasgupta, S. (1999): Gentamicin induced inhibition of steroidogenic enzymes in rat testis. Indian. J. Physiol. Pharmacol., 43, 247-250.

Goel, A., Dani, V. and Dawan, D. K. (2005): Protective effects of zinc on lipid peroxidation, antioxidant enzymes and hepatic histoarchitecture in chlorpyrifos induced toxicity. Chemico. Biol. Inter., 156, 131-140.

Hess, R.A. and Linder, R.E., Strader, L.F. and Perreault, S.D. (1988): Acute effects and long-term sequelae of 1,3-dinitrobenzene on male reproduction in the rat II. Quantitative and qualitative histopathology of the testis. J. Androl., 9, 327-342.

Hess, R.A., Nakai, M. (2000): Histopathology of the male reproductive system induced by the fungicide benomyl. Histol. Histopathol., 15, 207-224.

Kadkhodaee, M., Khastar, H., Arab, H.A., Ghaznavi, R., Zahmatkesh, M. and Mahdavi-Mazdeh, M. (2007): Antioxidant vitamins preserve superoxide dismutase activities in gentamicin-induced nephrotoxicity. Transplant. Proc., 39, 864-865.

Kaplan, L.A. and Pesce, P.J. (1987): Vitamins. In: Clinical chemistry. $2^{\text {nd }}$ Ed. CV Mosby Company, St. Louis, MO, pp.543.

Kataoka, N. (1983): Concentration of antimicrobial agents in male genital organs. Hinyokika. Kiyo., 29, 1219-1230.

Klibi, N., Ben Slama, K., Sáenz, Y., Masmoudi, A., Zanetti, S., Sechi, L. A., Boudabous, A. and Torres, C. (2007): Detection of virulence factors in high-level gentamicin-resistant Enterococcus faecalis and Enterococcus faecium isolates from a Tunisian hospital. Can. J. Microbiol., 53, 372-379.

Latchoumycandane, C. and Mathur, P.P. (2002): Induction of oxidative stress in the rat testis after short term exposure to organochlorine pesticide methoxychlor. Arch. Toxicol., 76, 692-698.

Marklund, S. and Marklund, G. (1974): Involvement of superoxide anion radical in autooxidation of pyrogallol and convenient assay for superoxide dismutase. Eur. J. Biochem., 47, 469-474.

Mates, J.M., Perez-Gomez, C. and Nunez, D.C.I. (1999): Antioxidant enzymes and human diseases. Clin. Biochem., 32, 595-603.

Mostafa, B.E., Tawfik, S., Hefnawi, N.G., Hassan, M. A. and Ismail, F. A. (2007): The role of deferoxamine in the prevention of gentamicin ototoxicity: A histological and audiological study in guinea pigs. Acta. Otolaryngol., 127, 234-239.

Narayana, K., D'Souza, U.J.A. and Rao, K.P.S. (2002): Ribavirininduced sperm shape abnormalities in Wistar rat. Mutation. Res., 513, 193-196.

Narayana, K., Prashanthi, N., Nayanatara, A., Kumar, H.H., Abhilash, K. and Bairy, K.L. (2005a): Effects of methyl parathion (o,o-dimethyl o4-nitrophenyl phosphorothioate) on rat sperm morphology and sperm count, but not fertility, are associated with decreased ascorbic acid level in the testis. Mutation. Res., 588, 28-34.

Narayana, K., D’Souza, U.J.A., Prashanthi, N. and Ganesh, K. (2005b): 
K. Narayana

The antiviral drug ribavirin reversibly affects the reproductive parameters in the male Wistar rat. Folia. Morphol., 64, 65-71.

Narayana, K., Prashanthi, N., Nayanatara, A., Kumar, H.H., Abhilash, K. and Bairy, K.L. (2006a): Neonatal methyl parathion exposure affects the growth and functions of the male reproductive system in the adult rat. Folia. Morphol., 65, 26-33.

Narayana, K., Prashanthi, N., Nayanatara, A., Bairy, K. L. and D'Souza, U.J.A. (2006b): An organophosphate insecticide methyl parathion (oo-dimethyl o-4-nitrophenyl phosphorothioate) induces cytotoxic damage and tubular atrophy in the testis despite elevated testosterone level in the rat. J. Toxicol. Sci., 31, 177-189.

Podczasy, J.J. and Wei, R. (1988): Reduction of iodonitrotetralzolium violet by superoxide radicals. Biochem. Biophys. Res. Commun., 150, 1294-1298.

Ramsammy, L.S. and Kaloyanides, G.J. (1987): Effect of gentamicin on the transition temperature and permeability to glycerol of phosphatidylinositol containing liposomes. Biochem. Pharmacol., 36, 11791181.

Reynolds, J.E.F. (1993): Martindale, The Extrapharmacopoeia. $30^{\text {th }}$ Edition. London. The Pharmaceutical Press. 170-172. London. pp.236245.

Sayed-Ahmed, M.M. and Nagi, M.N. (2007): Thymoquinone supplementation prevents the development of gentamicin induced acute renal toxicity in rats. Clin. Exp. Pharmacol. Physiol., 34, 399-405.

Segovia, M., Jenkins, J.A., Paniagua-Chavez, C. and Tlersch, T.R. (2000): Flow cytometric evaluation of antibiotic effects on viability and mitochondrial function of refrigerated spermatozoa of Nile tilapia. Theriogenology., 7, 1489-1499.

Sonmez, M., Turk, G. and Yuce, A. (2005): The effect of ascorbic acid supplementation on sperm quality, lipid peroxidation and testosterone levels of male Wistar rats. Theriogenology, 63, 2063-2072.

Timmermans, L.M. (1989): Modification of spermatogenesis following antibiotic therapy. Acta. Urol. Belg., 57, 35-46.

Tramer, F., Rocco, F., Micali, F., Sandri, G. and Panfili, E. (1998): Antioxidant systems in rat epididymal spermatozoa. Biol. Reprod., 59, 753-758.

Varley, H., Gowenlock, A.H. and Bell, M. (1980): Practical clinical chemistry. Vol 1. $5^{\text {th }}$ Ed, pp 451-921.Vam Heinemann Medical Books Ltd. London.

Walker, P.D., Barri, Y. and Shah, S.V. (1999): Oxidant mechanisms in gentamicin nephrotoxicity. Renal. Fail., 21, 433-442.

Wyrobek, A.J., Gordon, L.A., Burkhart, J.G., Francis, M.W., Kapp, R.W., Letz, G., Malling, H.V., Topham, J.C. and Whorton, M.D (1983): An evaluation of mouse sperm morphology test and other sperm tests in non human mammals. Mutation. Res., 115, 1-72. 